\title{
Prevalence of Nasal colonization with Staphylococcus aureus in 4 cities in Peru
}

\author{
Joan Neyra ${ }^{1 *}$, Michael Ellis ${ }^{2}$, Claudio Rocha ${ }^{1}$, Juan Silvera ${ }^{3}$, Moisés Apolaya $^{3}$, Maruja Bernal ${ }^{1}$, Rina Meza', \\ Enrique Canal', Yocelinda Meza ${ }^{1}$ and David Blazes ${ }^{4}$
}

\begin{abstract}
Background: Antimicrobial resistance (AMR) is a growing public health threat around the world and is not well characterized in the developing setting. Specifically, there is a lack of information regarding nasal colonization with S. aureus and methicillin-resistant Staphylococcus aureus (MRSA) in Latin America and Peru.

Methods: This is the report of the baseline findings of a prospective cohort study followed up over 1 year at four geographically and ecologically distinct Peruvian Air Force bases in order to determine S. aureus nasal colonization prevalence and risk factors. Additionally, all MRSA isolates underwent molecular analysis which included pulsed-field gel electrophoresis and determination of virulence and resistance genes.

Results: We enrolled 756 military personnel. Anterior nares colonization with Staphylococcus aureus was detected in 73 of 756 participants (9.7\%) and MRSA was detected in 2 of 756 (0.3\%). Colonization rates differed significantly $(P=0.02)$ between geographic enrollment sites: Talara-4.3 \%, Iquitos-9.1 \%, Arequipa-14.0 \% and Lima-11.3\%. Risk factors for $\mathrm{S}$. aureus colonization included being male and a reported history of respiratory disease.

Conclusion: Overall, we found low prevalence of $S$. aureus and MRSA nasal colonization in this Peruvian military population. These findings contribute to the overall epidemiological understanding of S. aureus and MRSA in Latin America. The colonization rates which varied based on geographical location warrants further study.
\end{abstract}

Keywords: Antimicrobial resistance, Methicillin-resistant Staphylococcus aureus, Military personnel

\section{Background}

The increasing prevalence of methicillin-resistant Staphylococcus aureus is a global problem, affecting military and non-military populations around the world. MRSA was first documented in 1960, and until the late 1990s, its presence was confined largely to hospital settings with occasional outbreaks. Since then, the number of outbreaks and infections caused by MRSA, specifically community-associated methicillin-resistant Staphylococcus aureus (CA-MRSA) strains increased steadily $[1,2]$. USA300 genotype is the predominant CA-MRSA strain recovered from outbreak investigations in U.S. and different countries in Europe and Asia, such as Japan [3], constituting a common cause of community associated skin and soft tissue infections (SSTIs).

\footnotetext{
* Correspondence: joaneyra11@gmail.com

${ }^{1}$ Naval Medical Research Unit Nº 6 Lima-Peru (NAMRU-6), 655 Manco Capac

St., Miraflores, Lima, Peru

Full list of author information is available at the end of the article
}

Nasal colonization with Staphylococcus aureus or MRSA is a risk factor for subsequent infection by these bacteria [4, 5]. In non-Latin American populations, colonization status varies with approximately 20-30\% persistently colonized and $20 \%$ is intermittently colonized [6-8]. Colonization is facilitated by the anatomy of the nasal vestibule and the resistance of $S$. aureus to microbicide peptides in the mucus [9]. Nasal colonization appears to change during one's lifetime. Colonization begins shortly after birth, decreases during the first 5 years and then it increases until $50 \%$ are carriers between 6 and 12 years; and finally it decreases as children mature and become adults [10]. In the military setting, Staphylococcus aureus infections complicate combat-related injuries and produce skin and soft-tissue infections during deployments or training. Among U.S. soldiers, MRSA SSTIs represent a considerable burden, and nasal colonization is a risk factor for subsequent disease [1, 11-14]. For example, the cumulative incidence of SSTIs after 10 weeks of 
follow-up at training facilities in U.S. military trainees was $38 \%$ in MRSA-colonized subjects while in non-colonized it was only $2 \%$ [11].

The Centers for Disease Control and Prevention's (CDC) 2013 report on antibiotic resistant pathogens listed MRSA as one of the most serious threats, causing 80,461 severe infections and 11,285 deaths per year in the U.S., leading to a heavy burden of the healthcare system [15]. Similarly, the 2014 WHO Global Health Report on Antimicrobial Resistance reported that in all the WHO regions, MRSA prevalence of infections was above $20 \%$ and increased the risk of death and the associated healthcare costs [16, 17]. In Latin America, a surveillance network for resistant bacterial infections was organized in 1998 under Pan American Health Organization (PAHO) sponsorship; collecting data from specific national and regional hospitals with adequate laboratory infrastructure and resources. However, there is little information regarding the prevalence in other areas, so the geographic extent and the characteristics of MRSA infections in Latin America are not well described in terms of prevalence, isolates, and risk factors [18]. Our current knowledge indicates that four MRSA clones are the most prevalent in Latin America: Brazilian, Pediatric, Cordobes/Chilean and New York/Japan, with marked differences in virulence, antimicrobial resistance profile and geographical distribution [19].

In Peru, current information about MRSA is mostly limited to case reports or series from hospital-based samples from reference hospitals with appropriate protocols for lab procedures and resources. Unfortunately, these studies do not inform us about the prevalence of $S$. aureus nasal colonization nor the epidemiological characteristics in the community, especially in young at-risk populations such as military personnel. Our work was the first study to systematically determine the prevalence and the molecular characteristics of nasal colonization with Staphylococcus aureus and MRSA among a Peruvian military population in multiple cities in Peru. Herein, we report the baseline results of this study.

\section{Methods}

\section{Study design}

We conducted a prospective cohort study with 1 year of follow-up among active duty military personnel from four bases one in each region of the Peruvian Air Force (Lima, Arequipa, Talara, and Iquitos). This is the report of the baseline findings of this cohort. The study population included male and female military active duty personnel, between age 18 and 59 years, stationed at these bases with different climate characteristics (Iquitos is located in the jungle; Talara, in the northern desert coast, Lima at the central coast with mild to warm temperatures depending on the season, and Arequipa, which is located at high altitude in the southern highlands, with a dry and relatively cold climate). See Fig. 1.

\section{Study procedures}

We enrolled military personnel from four large bases in each Air Force region. After we obtained written informed consent, each participant completed a self-administered questionnaire about demographic and risk factors and provided a nasal swab. Investigators obtained a sample from the vestibular area of each of the nares, using $\mathrm{BD}$ BBL CultureSwabs ${ }^{\oplus}$ (BD Diagnostic, Sparks MD). Each nasal swab specimen was placed in a refrigerated container and later stored in a refrigerator at $4{ }^{\circ} \mathrm{C}$ until the time of the shipping to Naval Medical Research Unit- 6 lab (NAMRU-6). Once they arrived at NAMRU-6 Bacteriology lab, the time gap between sample collection and plating was 1 month.

\section{Lab procedures}

Labeled swabs were shipped to the Naval Medical Research Unit N 6 (NAMRU-6) located at Lima, Peru. Nasal culture specimens were placed in $5 \mathrm{ml}$ of tryptic soy broth (TSB) supplemented with $6.5 \% \mathrm{NaCl}$ and incubated for $18-24 \mathrm{~h}$ at $35^{\circ} \mathrm{C}$. After that time, a 75 microL aliquot was plated onto mannitol salt agar. Plates were incubated for up to $48 \mathrm{~h}$ at $37^{\circ} \mathrm{C}$ and inspected for yellow colonies characteristic of $S$. aureus. Identified isolates were sub cultured onto tryptic soy agar with $5 \%$ sheep blood. Subsequent colonies underwent catalase and coagulase testing per Micro Lab Standard Operational Procedures (SOP) at NAMRU-6. All confirmed S. aureus isolates collected from the nasal swabs were shipped to Uniformed Services University (USU)'s Laboratory where they underwent susceptibility testing using disk diffusion tests for identifying MRSA strains, following the standards established by the Clinical and Laboratory Standards Institute [20]. Additionally, all MRSA strains underwent pulsed field gel electrophoresis (PFGE) procedures. Using polymerase chain reaction (PCR) we detected Panton-Valentine Leukocidin (PVL), arginine catabolic mobile element (ACME), staphylococcal chromosome cassete (SCCmec) type, presence of toxic shock syndrome toxin (TST), gene ileS-2 for resistant to mupirocin (mupA), and tolerance to chlorhexidine (qacA/B) using standard protocols.[7].

\section{Statistical analysis}

Overall and baseline colonization status are described based on gender, rank, base of recruitment, age group, time of service in the Peruvian Air Force $(\leq 10$ years, 11-20 years, $>20$ years), type of activities, smoking status, previous hospitalizations in the last 12 months, previous deployments, use of antibiotics in the last 12 months, previous SSTIs in the last 12 months, previous respiratory diseases, use of corticosteroids in the 


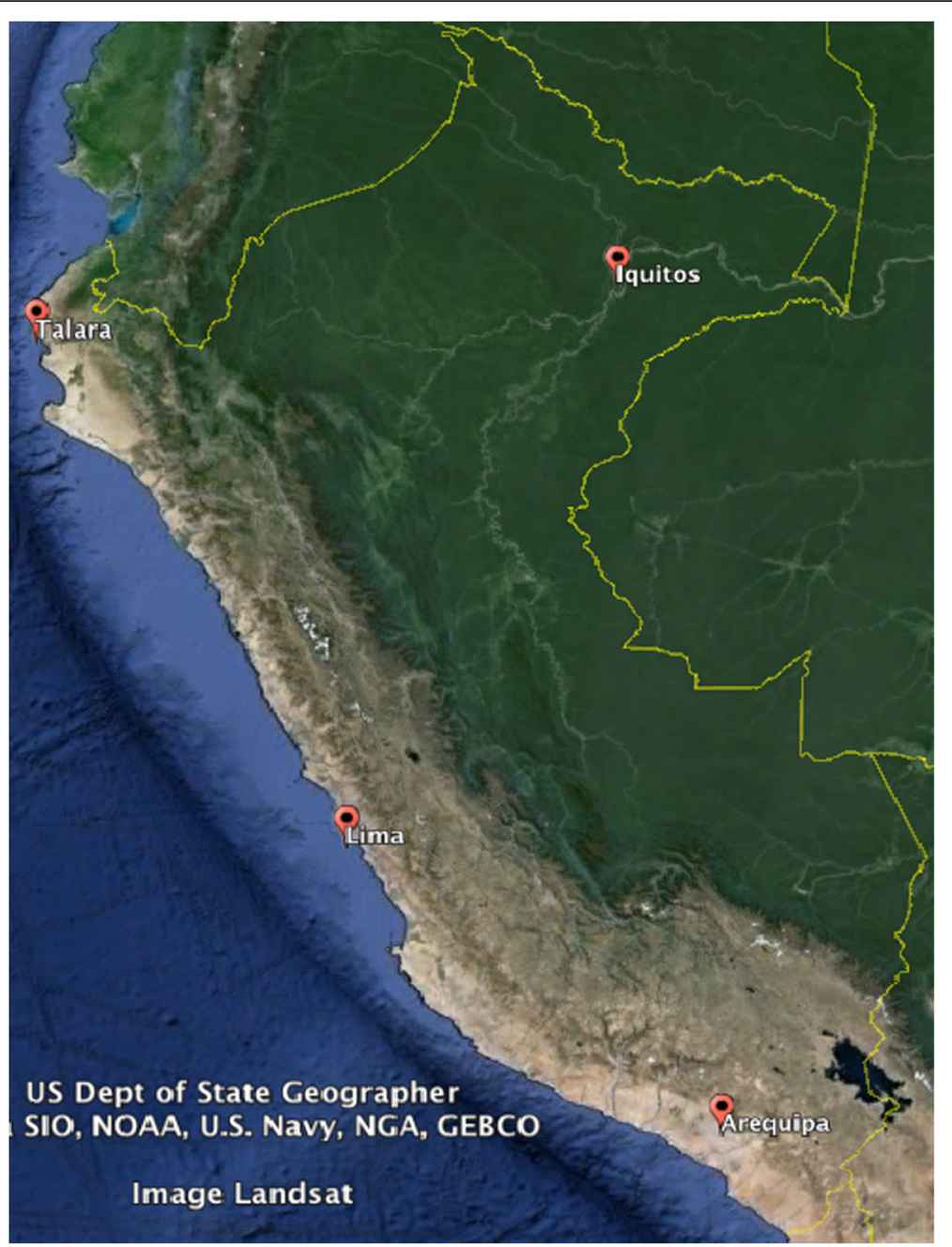

Fig. 1 Map of Peru showing the location of the four sites. Lima, the capital city of Peru is located at the central desert coast; Talara, in the northern desert coast; Arequipa, in the southern highlands; and lquitos is located in the northeastern jungle (Image taken from Google Earth)

last 12 months, place of residence, medical conditions; and is reported as numbers and proportions with twosided $95 \%$ confidence intervals. We also report the prevalence rate of nasal colonization with MRSA strains and the results of the antimicrobial susceptibility for those isolates positive to Staphylococcus aureus. We used a logistic regression model to determine the association with the variables listed above. The Institutional Review Boards at USU (Bethesda, MD, USA), and NAMRU-6 (Lima Peru) approved the research protocol.

\section{Results}

\section{Demographic and clinical characteristics}

We enrolled 756 participants. The mean age of the participants was $30.3 \pm 11.5$ years, but almost $60 \%$ of our study population was younger than 30 years. Slightly more than $80 \%$ were male and $61 \%$ of the participants had more than 10 years of military service. Almost $90 \%$ of the study population included Non-Commissioned officers and troops, and their occupations included administrative (32.5\%), instructional (36.5\% and combat $(29.2 \%)$ activities. We found that $20.1 \%$ of the participants had a reported medical condition. Of them, $10 \%$ reported gastrointestinal diseases, $5.4 \%$ reported a skin disease, $2.6 \%$ reported a respiratory disease, and $1.1 \%$ reported an infectious disease. More than a third of the participants $(34.8 \%)$ reported the use of antibiotics during the previous year; of these, $52 \%$ (136) gave a specific antibiotic. In addition, $20.2 \%$ reported the use of corticosteroids; and $11.6 \%$ of the enrolled participants were hospitalized during the previous year. Regarding the diagnosis of any SSTI during the previous year, only $5.8 \%$ reported a SSTI. Smoking was common: $34.2 \%$ were 
current smokers, $16.7 \%$ were past smokers, and $45.6 \%$ reported never smoking (Table 1 ).

\section{Baseline nasal colonization with Staphylococcus aureus and MRSA}

The baseline nasal colonization prevalence among the 756 enrolled participants was $9.7 \%$. There were two periods of recruitment, in October-November 2013 (655 participants) and April-August 2014 (101 participants), and the baseline nasal colonization rates for each period were similar ( $9.8 \%$ vs. $8.9 \%, p=0.7853$, Z-statistic for comparison of two proportions). The overall rate of colonization with MRSA was $0.3 \%$ during the study period ( 2 of 756 ). These isolates were collected during the 6 month visit at Arequipa, one in a participant enrolled in October 2013 and a second from a different participant who was enrolled in in May 2014). Molecular analysis of these MRSA isolates demonstrated that they possessed SCCmec type IV and qacA/B (chlorhexidine tolerance), but lacked genes for PVL, mupirocin resistance, and toxic shock syndrome toxin (TST).

Table 2 shows statistically significant associations between prevalence of nasal colonization at baseline and demographic and clinical variables. Those participants between 18 and 29 years old and 40 to 49 years old had a higher prevalence of nasal colonization $(10.2 \%$ vs. $11.3 \%$ ); while, the prevalence was lower than $7 \%$ for other age groups. Nasal colonization was greater in male than female $(10.3$ vs. $6.8 \%, p=0.201)$. The troops had $11.5 \%$ of nasal baseline nasal colonization, higher than officers or non-commissioned officers (9.5 \% vs. $8.2 \%$ ). There was a statistically significant difference in the distribution of nasal colonization by base of recruitment $(p=0.023)$; Talara had the lowest baseline prevalence $(4.3 \%)$ compared to the other three bases that had similar rates (Iquitos-9.1 \%, Arequipa-14.0 \% and Lima-11.3 \%). Those who lived on base but not in the barracks had the lowest prevalence (5.3\%) but this was not significantly $(p=0.198)$ different from those who lived at the barracks (11.2 \%) and those who lived off the base (9.9\%).

Having a respiratory disease increases the prevalence of nasal colonization (30\%) compared with those without respiratory disease $(9.1 \%, p=0.002)$. Smoking did not affect the prevalence of nasal colonization; the rates were similar among those who never smoked (8.1\%), previous smokers $(12.7 \%)$ and currently smokers $(10.4 \%) \quad(p=0.300)$ (Table 3).

Among those who used antibiotics during the last year, the nasal colonization prevalence at baseline was not different among those who used them (11.0\%) or not (9.1\%). However, when we analyzed the use of dicloxacillin the previous year, those who reported its use had a $33.3 \%$ prevalence of nasal colonization, compared with those who did not report its use $(9.3 \%, p=0.005)$. Regarding the use of corticosteroids, those who used them the previous year, had a prevalence of $12.4 \%$, which was similar to those who did not use them (8.9\%), ( $p=: 0.432)$.

In terms of hospitalization during the previous year, the rates were similar among those who were hospitalized $(10.2 \%)$ and those who were not $(9.6 \%)(p=0.971)$. Similarly there was no difference in prevalence between those who had the diagnosis of SSTIs during the last year $(9.1 \%)$ and those who did not $(9.5 \%)$. The identified risk factors for $\mathrm{S}$. aureus colonization included being male and a reported history of respiratory disease; while time of service had a slight protective effect.

\section{Antimicrobial susceptibility of positive isolates and MRSA isolates}

NAMRU-6 and USUHS labs processed 183 positive Staphylococcus aureus samples from the participants during the study period (1 year). Antimicrobial susceptibility is reported in Table 3 . The highest resistance was to erythromycin (16.4\%). In addition, $6.6 \%$ had an inducible resistance to clindamycin. All isolates were susceptible to ceftaroline, trimethoprim-sulfamethoxazole, vancomycin, and linezolid (Table 4).

\section{Discussion}

\section{Baseline prevalence}

There are only a few studies of nasal colonization in active duty military populations, primarily from the US and one from China, but none in Peru or Latin America. These studies found that the prevalence of colonization in American recruits was $31 \%$ [11], while the Chinese military found a different rate depending if individuals were deployed to urban (24.6\%) or suburban military centers $(16.1 \%)$ [21]. In both cases, the prevalence was higher than what we found at baseline in our study population $(9.7 \%)$. Only two previous studies were performed in community settings in Peru. One study included only children from Cajamarca and found a prevalence of $11.9 \%$ [22], while the second included inhabitants of an impoverished community of Lima, and found that among adults of different ages the prevalence of nasal colonization ranged from 20.4 to $39.6 \%$ [23]. These two previous studies in Peru are comparable with others studies performed in Latin American countries that showed that the nasal colonization rates with Staphylococcus aureus in community settings was quite varied. In adult populations, the nasal colonization rates in Brazil ranged between $32.7 \%$ [24] and $40.8 \%$ [25]; while among Colombian medical students the rate was $25 \%$ [26]. The prevalence we obtained in the Peruvian military was closer to the prevalence rate reported among adult students in Nigeria (14\%) and healthcare workers in Nicaragua (6.7 to $11.6 \%$ ) [27, 28]. In Peru, 3 MRSA strains from Peruvian citizens returning 
Table 1 Demographic characteristics of study participants

\begin{tabular}{|c|c|c|}
\hline Variable & $\begin{array}{l}\text { Frequency } \\
(N=756)\end{array}$ & Percentage (\%) \\
\hline \multicolumn{3}{|l|}{ Age } \\
\hline $18-29$ years & 450 & 59.5 \\
\hline $30-39$ years & 95 & 12.6 \\
\hline $40-49$ years & 151 & 20.0 \\
\hline 50 years or more & 60 & 7.9 \\
\hline \multicolumn{3}{|l|}{ Time of service } \\
\hline 10 years or less & 463 & 61.2 \\
\hline $11-20$ years & 103 & 13.6 \\
\hline 20 years or more & 190 & 25.1 \\
\hline \multicolumn{3}{|l|}{ Sex } \\
\hline Female & 146 & 19.3 \\
\hline Male & 610 & 80.7 \\
\hline \multicolumn{3}{|l|}{ Rank } \\
\hline Officers & 84 & 11.1 \\
\hline Non-Commissioned Officers & 368 & 48.7 \\
\hline Troops & 304 & 40.2 \\
\hline \multicolumn{3}{|l|}{ Base of recruitment } \\
\hline lquitos & 253 & 33.5 \\
\hline Arequipa & 164 & 21.7 \\
\hline Talara & 162 & 21.4 \\
\hline Lima & 177 & 23.4 \\
\hline \multicolumn{3}{|l|}{ Administrative activities } \\
\hline No & 510 & 67.5 \\
\hline Yes & 246 & 32.5 \\
\hline \multicolumn{3}{|l|}{ Instruction activities } \\
\hline No & 483 & 63.9 \\
\hline Yes & 273 & 36.1 \\
\hline \multicolumn{3}{|l|}{ Combat activities } \\
\hline No & 535 & 70.8 \\
\hline Yes & 221 & 29.2 \\
\hline \multicolumn{3}{|l|}{ Number of activities } \\
\hline Not related & 106 & 14.0 \\
\hline Unique & 580 & 76.7 \\
\hline Multiple & 70 & 9.3 \\
\hline \multicolumn{3}{|l|}{ Place of residence } \\
\hline Barracks & 250 & 33.1 \\
\hline Inside the base & 114 & 15.1 \\
\hline Outside the base & 392 & 51.9 \\
\hline \multicolumn{3}{|l|}{ Medical conditions } \\
\hline No & 604 & 79.9 \\
\hline Yes & 152 & 20.1 \\
\hline \multicolumn{3}{|l|}{ Number of medical conditions } \\
\hline None & 604 & 79.9 \\
\hline
\end{tabular}

Table 1 Demographic characteristics of study participants (Continued)

\begin{tabular}{lll}
\hline One disease & 118 & 15.6 \\
More than one disease & 34 & 4.5 \\
Use of antibiotics in the previous year & & \\
No & 427 & 56.5 \\
Yes & 263 & 34.8 \\
Unknown & 66 & 8.7 \\
Use of corticosteroids in the previous year & & \\
No & 536 & 70.9 \\
Yes & 153 & 20.2 \\
Unknown & 67 & 8.9 \\
Hospitalized during the previous year & & \\
No & 645 & 85.3 \\
Yes & 88 & 11.6 \\
Unknown & 23 & 3.0 \\
Diagnosis of SST/s during the previous year & & \\
No & 671 & 88.8 \\
Yes & 44 & 5.8 \\
Unknown & 41 & 5.4 \\
Smoking status & & \\
Never & 345 & 45.6 \\
Past smoker & 126 & 16.7 \\
Current smoker & 259 & 34.2 \\
\hline
\end{tabular}

from abroad were characterized in 2011, one was ST30 and the other two were ST8 clones which are related to the USA300 clone [29].

We found differences in the prevalence of nasal colonization based on the site of the geographical site if study enrollment. Of the four sites, Lima is the capital city of Peru (approximately 10 million inhabitants), while Arequipa (900,000 inhabitants) and Iquitos (420,000 inhabitants) are the most important urban centers in the highlands and the jungle and had higher prevalence rates; while Talara, which is a smaller city than the other three (101,000 inhabitants), had only $4.3 \%$. This colonization prevalence differences may be attributed to a number of factors including climate and ecology, population size, or access to healthcare. An important aspect of population size is that it generally suggests differences in commercial movement, and therefore access to common antibiotics that are still sold without a medical prescription at small pharmacies and drugstores. Additionally, the distribution of antibiotics to each military health facility is based on the most prevalent diseases and the size of the base, which are larger in Lima, Arequipa and Iquitos where administrative and operational regional offices are located, and therefore exceed 
Table 2 Prevalence of baseline nasal colonization among the different variables under study $(N=756)$

\begin{tabular}{|c|c|c|c|}
\hline \multirow[t]{2}{*}{ Variable } & \multicolumn{2}{|c|}{ Baseline Nasal colonization (\%, $95 \%$ Cl) } & \multirow[t]{2}{*}{$P$ value } \\
\hline & Positive $(n=73)$ & Negative $(n=683)$ & \\
\hline \multicolumn{4}{|l|}{ Age } \\
\hline $18-29$ years & $10.2(7.4-13.0)$ & $89.8(86.9-92.6)$ & \multirow[t]{4}{*}{$0.537^{\mathrm{a}}$} \\
\hline $30-39$ years & $6.3(1.4-11.2)$ & $93.7(88.8-98.6)$ & \\
\hline $40-49$ years & $11.3(6.2-16.3)$ & $88.7(83.7-93.8)$ & \\
\hline 50 years or more & $6.7(0.3-13.0)$ & $93.3(86.9-99.7)$ & \\
\hline \multicolumn{4}{|l|}{ Time of service } \\
\hline 10 years or less & $10.6(7.8-13.4)$ & $89.4(86.6-92.2)$ & \multirow[t]{3}{*}{0.334} \\
\hline $11-20$ years & $5.8(1.3-10.4)$ & $94.2(89.6-98.7)$ & \\
\hline 20 years or more & $9.5(5.3-13.7)$ & $90.5(86.3-94.7)$ & \\
\hline \multicolumn{4}{|l|}{ Sex } \\
\hline Female & $6.8(2.7-10.9)$ & $93.2(89.0-97.3)$ & \multirow[t]{2}{*}{0.201} \\
\hline Male & $10.3(7.9-12.7)$ & $89.7(87.3-92.1)$ & \\
\hline \multicolumn{4}{|l|}{ Rank } \\
\hline Officers & $9.5(3.2-15.8)$ & $90.5(84.2-96.8)$ & \multirow[t]{3}{*}{0.340} \\
\hline Non-Commissioned Officers & $8.2(5.3-10.9)$ & $91.8(89.0-94.7)$ & \\
\hline Troops & $11.5(7.9-15.1)$ & $88.5(84.9-92.1)$ & \\
\hline \multicolumn{4}{|l|}{ Base of recruitment } \\
\hline lquitos & $9.1(5.5-12.6)$ & $90.9(87.4-94.5)$ & \multirow[t]{4}{*}{0.023} \\
\hline Arequipa & $14.0(8.7-19.4)$ & $85.9(80.6-91.3)$ & \\
\hline Talara & $4.3(11.8-7.5)$ & $95.7(92.5-98.8)$ & \\
\hline Lima & $11.3(6.6-15.9)$ & $88.7(84.0-93.4)$ & \\
\hline \multicolumn{4}{|l|}{ Number of activities } \\
\hline Not related & $10.4(4.5-16.2)$ & $89.6(83.8-95.5)$ & \multirow[t]{3}{*}{0.587} \\
\hline Unique & $9.1(6.8-11.5)$ & $90.9(88.5-93.2)$ & \\
\hline Multiple & $12.9(4.9-20.8)$ & $87.1(79.2-95.1)$ & \\
\hline \multicolumn{4}{|l|}{ Number of medical conditions } \\
\hline None & $9.9(7.5-12.3)$ & $90.1(87.7-92.5)$ & \multirow[t]{3}{*}{0.122} \\
\hline One disease & $6.1(1.7-10.5)$ & $93.9(89.5-98.3)$ & \\
\hline More than one disease & $17.6(4.6-30.7)$ & $82.4(69.3-95.4)$ & \\
\hline \multicolumn{4}{|c|}{ Respiratory diseases the previous year } \\
\hline No & $9.1(7.0-11.2)$ & $90.9(88.8-92.9)$ & \multirow[t]{2}{*}{0.002} \\
\hline Yes & $30.0(9.4-50.6)$ & $70.0(49.4-90.6)$ & \\
\hline \multicolumn{4}{|l|}{ Use of antibiotics the previous year } \\
\hline No & $9.1(6.4-11.9)$ & $90.9(88.1-93.6)$ & \multirow[t]{3}{*}{0.598} \\
\hline Yes & $11.0(7.2-14.8)$ & $88.9(85.2-92.8)$ & \\
\hline Unknown & $7.6(11.3-14.0)$ & $92.4(85.9-98.9)$ & \\
\hline \multicolumn{4}{|l|}{ Use of dicloxacillin previous year } \\
\hline No & $9.3(7.2-11.4)$ & $90.7(88.6-92.8)$ & \multirow[t]{2}{*}{0.005} \\
\hline Yes & $33.3(5.4-61.2)$ & $66.7(38.8-94.6)$ & \\
\hline \multicolumn{4}{|c|}{ Use of corticosteroids the previous year } \\
\hline No & $8.9(6.5-11.4)$ & $91.0(88.6-93.5)$ & \multirow[t]{3}{*}{0.432} \\
\hline Yes & $12.4(7.2-17.7)$ & $87.6(82.3-92.8)$ & \\
\hline Unknown & $8.9(2.1-15.9)$ & $91.0(84.1-97.9)$ & \\
\hline
\end{tabular}


Table 2 Prevalence of baseline nasal colonization among the different variables under study $(N=756)$ (Continued)

\begin{tabular}{lll}
\hline Hospitalized during the previous year & & \\
No & $9.6(7.3-11.9)$ & $90.4(88.1-92.7)$ \\
Yes & $10.2(3.8-16.6)$ & $89.8(83.4-96.2)$ \\
Unknown & $8.7(0.0-20.5)$ & $91.2(79.5-100)$ \\
Diagnosis of SSTIs during the previous year & & \\
No & $9.5(7.3-11.8)$ & $90.5(88.2-92.7)$ \\
Yes & $9.1(0.5-17.7)$ & $90.9(82.3-99.5)$ \\
Unknown & $12.2(5.2-22.4)$ & $87.8(77.6-97.9)$ \\
Smoking status & & $91.9(88.9-94.8)$ \\
Never & $8.1(5.2-11.0)$ & $87.3(81.5-93.1)$ \\
Past smoker & $12.7(6.9-18.5)$ & $89.6(85.8-93.3)$ \\
Current smoker & $10.4(6.7-14.2)$ & \\
Place of residence & & $88.8(84.9-92.7)$ \\
Barracks & $11.2(7.3-15.1)$ & $94.7(90.6-98.9)$ \\
Inside the base & $5.3(1.1 .-9.4)$ & $90.1(87.1-93.0)$ \\
Outside the base & $9.9(6.9-12.9)$ & 0.297
\end{tabular}

${ }^{a}$ We used the Fisher's exact test. For the rest of the variables, we used the Pearson chi square test

the population assigned to Talara, which is only an operational base. The increased exposure to antibiotics in Lima, Iquitos and Arequipa might favor the development of nasal colonization with Staphylococcus aureus by eliminating other commensal bacteria colonizing the human nares; unfortunately information regarding the most used antibiotics at each of the bases or local areas is currently unavailable.

Dicloxacillin is an antibiotic belonging to the beta lactam family that is used extensively for the treatment of SSTIs. We had expected that the use of dicloxacillin might reduce the rates of nasal colonization with Staphylococcus aureus, but we found the opposite. Possibly, the normal microbiota in the anterior nares is more susceptible than Staphylococcus aureus to dicloxacillin, therefore favoring the Staphylococcus aureus growth. Another possible reason can be the misuse of this antibiotic, which is usually prescribed for 7 to 14 days, but if the dose and time of prescription were not adequate, the antibiotic might have limited effect. We were not able to collect information regarding the dose, time of prescription, where the antibiotics were purchased, or if the treatment was completed.

We identified only two participants with MRSA and therefore our overall prevalence of MRSA colonization during the study period was $0.3 \%$ ( 2 of 756 ). These isolates possessed SCCmec type IV which is the characteristic mobile genetic element carrying the mecA gene (methicillinresistance) found most commonly in CA-MRSA strains. Our MRSA colonization prevalence was close to those reported in previous studies in Peru and Latin America, where it ranges from 0.6 to $1.8 \%[23,30,31]$ in communities; however these proportions are lower than those observed in developed countries like US or Europe. In terms of military populations, our results reflect that MRSA nasal colonization is lower than rates reported in US military populations (3\%), while the Chinese study did not detect any MRSA [11, 21].

Our questionnaire was not designed to provide more specific historical information regarding the type of SSTI and treatments prescribed, dose and timing of antibiotics and corticosteroids, time of hospitalization, place, and antibiotics used during this time, which could have given us more detailed information regarding these risk factors. Also, given that this was a self-administered questionnaire, there is the potential for recall bias. In addition, it is possible that some participants did not understand the questions asked or did not know the medical terms used; therefore they left the questions blank. In addition, it is possible that sample handling could have affected the recovery of positive $S$. aureus isolates, specifically during the sampling procedure due to discomfort of the participants that led to movements of the head and a poor quality sample, and the limited available timeframe we had for doing it. Different climate conditions at each site may have affected also the recovery due to the use of a refrigerated container that could not have kept a low temperature at all times.

We believe our results can serve as a proxy to understanding of the nasal colonization with Staphylococcus 
Table 3 Potential risk factors associated with baseline nasal colonization with Staphylococcus aureus

\begin{tabular}{|c|c|c|c|c|}
\hline Variable & $\mathrm{N}$ & $\begin{array}{l}\text { Unadjusted } \\
\text { OR }\end{array}$ & $\begin{array}{l}\text { Adjusted OR } \\
(95 \% \mathrm{Cl})\end{array}$ & $P$-value \\
\hline \multicolumn{5}{|c|}{$\begin{array}{l}\text { Use of antibiotics during } \\
\text { the previous year }\end{array}$} \\
\hline No & 400 & Ref & Ref & \\
\hline Yes & 238 & 1.2 & $1.4(0.8-2.6)$ & 0.283 \\
\hline \multicolumn{5}{|c|}{$\begin{array}{l}\text { Hospitalization during } \\
\text { the previous year }\end{array}$} \\
\hline No & 566 & Ref & Ref & \\
\hline Yes & 72 & 1.0 & $1.0(0.4-2.4)$ & 0.980 \\
\hline \multicolumn{5}{|c|}{$\begin{array}{l}\text { Diagnosis of SSTI } \\
\text { during the previous year }\end{array}$} \\
\hline No & 600 & Ref & Ref & \\
\hline Yes & 38 & 0.5 & $0.4(0.1-1.8)$ & 0.237 \\
\hline \multicolumn{5}{|l|}{ Sex } \\
\hline Female & 122 & Ref & Ref & \\
\hline Male & 516 & 1.8 & $2.4(1.0-5.7)$ & 0.043 \\
\hline \multicolumn{5}{|l|}{ Base of recruitment } \\
\hline Talara & 144 & Ref & Ref & \\
\hline Iquitos & 207 & 2.5 & $2.5(0.9-6.5)$ & 0.065 \\
\hline Lima & 149 & 2.8 & $2.7(0.9-7.3)$ & 0.051 \\
\hline Arequipa & 138 & 3.9 & $4.5(1.7-11.9)$ & 0.002 \\
\hline \multicolumn{5}{|l|}{ Smoking status } \\
\hline Never smoked & 312 & Ref & Ref & \\
\hline Past smoker & 107 & 1.7 & $1.6(0.8-3.5)$ & 0.204 \\
\hline Current smoker & 219 & 1.2 & $1.1(0.6-2.1)$ & 0.756 \\
\hline \multicolumn{5}{|l|}{ Respiratory diseases } \\
\hline No & 619 & Ref & Ref & \\
\hline Yes & 19 & 3.5 & $4.5(1.4-14.7)$ & 0.014 \\
\hline Time of service & 638 & 0.99 & $0.97(0.94-0.99)$ & 0.030 \\
\hline
\end{tabular}

aureus in the community. We found that these isolates have a remarkable antimicrobial susceptibility with very little resistance when compared with other populations. This susceptibility may allow us an optimization of the current treatment of different infections where Staphylococcus aureus is a common etiologic agent. This standardization should help to reduce the indiscriminate exposure to more expensive and broader spectrum antibiotics that should be left as second or third line options, which are more expensive and increase the risk of adverse reactions.

\section{Conclusions}

In summary, we found a low prevalence of baseline nasal colonization with Staphylococcus aureus (9.7 \%) and MRSA $(0.3 \%)$ in an active duty military population in
Table 4 Antimicrobial susceptibility of 183 Staphylococcus aureus isolates

\begin{tabular}{llll}
\hline Antibiotic & \multicolumn{3}{l}{ Number (\%) of samples } \\
\cline { 2 - 4 } & Susceptible & Resistant & Intermediate \\
\hline Clindamycin $^{\text {a }}$ & $179(97.8)$ & $4(2.2)$ & - \\
Erythromycin & $153(83.6)$ & $30(16.4)$ & - \\
Doxycycline & $180(98.4)$ & - & $3(1.6)$ \\
Linezolid & $183(100)$ & - & - \\
Oxacillin & $181(98.9)$ & $2(1.1)$ & - \\
Rifampin & $183(100)$ & - & - \\
TMP-SMX ${ }^{b}$ & $183(100)$ & - & - \\
Vancomycin & $183(100)$ & - & - \\
Gentamicin & $177(96.7)$ & $6(3.3)$ & - \\
Levofloxacin & $182(99.5)$ & $1(0.5)$ & - \\
Ceftaroline & $183(100)$ & - & - \\
\hline
\end{tabular}

a $6.6 \%$ of the samples showed inducible resistance to clindamycin

${ }^{\text {b}}$ TMP-SMX, trimethoprim-sulfamethoxazole

Peru. Our results increase the current knowledge about Staphylococcus aureus nasal colonization in Peru and Latin America. Further study exploring the geographically differences in $S$. aureus nasal colonization warrants further investigation.

\section{Abbreviations \\ AMR, Antimicrobial resistance; MRSA, methicillin-resistant Staphylococcus aureus; SCCmec, staphylococcal cassette chromosome mec}

\section{Acknowledgments}

None.

\section{Funding}

This research was funded by the Global Emerging Infections Surveillance and Response System (GEIS) of the Armed Forces Health Surveillance Branch. Ref, Number: P0004_12_HS.

\section{Availability of data and materials}

Data will not be shared since participants belong to the Peruvian Armed Forces and it contains sensitive information.

\section{Authors' contributions}

JN was responsible for developing the study protocol, obtaining IRB approval, overseeing the implementation of the study, coordinating and providing general oversight to all research efforts and performed data collection and analysis. DB oversaw the implementation of the study protocol as well as the manuscripts writing. ME was responsible for sample testing, sequencing and characterization of MRSA strains at USUHS. CR provided oversight of the laboratory diagnostic procedures at NAMRU-6 and helped during the sample collection at the study sites. MA was in charge of coordination with the Peruvian Air Force, provided general oversight to the data collection from all the Peruvian Air Force establishments. JS helped with the sample collection at the study sites and with the coordination for data collection of SSTIs at each health establishment. RM, YM, MB, EC performed the sample identification, molecular tests and antimicrobial susceptibility tests at NAMRU-6 Bacteriology labs. All authors read and approved the final manuscript.

Competing interests

The authors declare that they have no competing interests. 


\section{Consent for publication}

We report aggregated data from the participants. During the consent process we asked for consent to publish form the participants.

\section{Ethics approval and consent to participate}

The protocol was approved by the Institutional Review Board of U.S. Naval Medical Research Unit No. 6, Lima-Peru (NAMRU-6), Ref. number NAMRU6.2013.0021.

Each study participant signed an informed consent previous to enrollment.

\section{Author details}

'Naval Medical Research Unit Nº 6 Lima-Peru (NAMRU-6), 655 Manco Capac St., Miraflores, Lima, Peru. ${ }^{2}$ University of Toledo College of Medicine and Life Sciences, Toledo, USA. ${ }^{3}$ Peruvian Air Force, Lima, Peru. ${ }^{4}$ Uniformed Services University (USU), Bethesda, USA.

Received: 5 March 2016 Accepted: 7 June 2016

Published online: 22 July 2016

\section{References}

1. David MZ, Daum RS. Community-associated methicillin-resistant Staphylococcus aureus: epidemiology and clinical consequences of an emerging epidemic. Clin Microbiol Rev. 2010;23(3):616-87.

2. Wallin TR, Hern HG, Frazee BW. Community-associated methicillin-resistant Staphylococcus aureus. Emerg Med Clin North Am. 2008:26(2):431-55. ix.

3. Tenover FC, McAllister S, Fosheim G, McDougal LK, Carey RB, Limbago B, Lonsway D, Patel JB, Kuehnert MJ, Gorwitz R. Characterization of Staphylococcus aureus isolates from nasal cultures collected from individuals in the United States in 2001 to 2004. J Clin Microbiol. 2008:46(9): 2837-41.

4. Kluytmans JA, Mouton JW, ljzerman EP, Vandenbroucke-Grauls CM, Maat AW, Wagenvoort JH, Verbrugh HA. Nasal carriage of Staphylococcus aureus as a major risk factor for wound infections after cardiac surgery. J Infect Dis. 1995; 171(1):216-9.

5. von Eiff C, Becker K, Machka K, Stammer H, Peters G. Nasal carriage as a source of Staphylococcus aureus bacteremia. Study Group N Engl J Med. 2001;344(1):11-6.

6. Boyce J. Epidemiology of methicillin-resistan Staphylococcus aureus infection in adults. In., June 16, 2010 edn: UpToDate 2010; 2010

7. Ellis MW, Griffith ME, Jorgensen JH, Hospenthal DR, Mende K, Patterson JE. Presence and molecular epidemiology of virulence factors in methicillinresistant Staphylococcus aureus strains colonizing and infecting soldiers. J Clin Microbiol. 2009:47(4):940-5.

8. Frank DN, Feazel LM, Bessesen MT, Price CS, Janoff EN, Pace NR. The human nasal microbiota and Staphylococcus aureus carriage. PLoS One. 2010;5(5):e10598.

9. Wertheim HF, Melles DC, Vos MC, van Leeuwen W, van Belkum A, Verbrugh HA, Nouwen JL. The role of nasal carriage in Staphylococcus aureus infections. Lancet Infect Dis. 2005;5(12):751-62.

10. Sollid JU, Furberg AS, Hanssen AM, Johannessen M. Staphylococcus aureus: determinants of human carriage. Infect Genet Evol. 2014;21:531-41.

11. Ellis MW, Hospenthal DR, Dooley DP, Gray PJ, Murray CK. Natural history of community-acquired methicillin-resistant Staphylococcus aureus colonization and infection in soldiers. Clin Infect Dis. 2004;39(7):971-9.

12. Mehndiratta PL, Bhalla P. Typing of Methicillin resistant Staphylococcus aureus: a technical review. Indian J Med Microbiol. 2012;30(1):16-23.

13. Patel M. Community-associated meticillin-resistant Staphylococcus aureus infections: epidemiology, recognition and management. Drugs. 2009;69(6): 693-716.

14. Tenover FC, Goering RV. Methicillin-resistant Staphylococcus aureus strain USA300: origin and epidemiology. J Antimicrob Chemother. 2009;64(3):441-6.

15. Control CfD. Antibiotic Resistance Threats in the United States, 2013. 2013:114.

16. Organization WH. Antimicrobial Resistance. Global Report on Surveillance 2014. 2014:232

17. Lee BY, Singh A, David MZ, Bartsch SM, Slayton RB, Huang SS, Zimmer SM, Potter MA, Macal CM, Lauderdale DS, et al. The economic burden of community-associated methicillin-resistant Staphylococcus aureus (CA-MRSA). Clin Microbiol Infect. 2013;19(6):528-36.

18. Mejia C, Zurita J, Guzman-Blanco M. Epidemiology and surveillance of methicillin-resistant staphylococcus aureus in Latin America. Braz J Infect Dis. 2010;14 Suppl 2:S79-86.
19. Rodriguez-Noriega E, Seas C. The changing pattern of methicillin-resistant staphylococcus aureus clones in Latin America: implications for clinical practice in the region. Braz J Infect Dis. 2010;14 Suppl 2:S87-96.

20. Wikler MA. Performance standards for antimicrobial susceptibility testing; 16th informational supplement. Wayne: Institute CaLS; 2007. p. 1523-30.

21. Qu F, Cui E, Guo T, Li H, Chen S, Liu L, Han W, Bao C, Mao Y, Tang YW. Nasal colonization of and clonal transmission of methicillin-susceptible Staphylococcus aureus among Chinese military volunteers. J Clin Microbiol. 2010;48(1):64-9.

22. Chien YW, Vidal JE, Grijalva CG, Bozio C, Edwards KM, Williams JV, Griffin MR, Verastegui $\mathrm{H}$, Hartinger SM, Gil Al, et al. Density interactions among Streptococcus pneumoniae, Haemophilus influenzae and Staphylococcus aureus in the nasopharynx of young Peruvian children. Pediatr Infect Dis J. 2013;32(1):72-7.

23. Carmona E, Sandoval S, Garcia C. The frequency and antibiotic susceptibility of Staphylococcus aureus from nasal swabs in an suburban marginal population in Lima, Peru. Rev Peru Med Exp Salud Publica. 2012;29(2):206-11.

24. Pires FV, da Cunha ML, Abraao LM, Martins PY, Camargo CH, Fortaleza CM. Nasal carriage of Staphylococcus aureus in Botucatu, Brazil: a populationbased survey. PLoS One. 2014;9(3):e92537.

25. Prates KA, Torres AM, Garcia LB, Ogatta SF, Cardoso CL, Tognim MC. Nasal carriage of methicillin-resistant Staphylococcus aureus in university students. Braz J Infect Dis. 2010;14(3):316-8.

26. Bettin A, Causil C, Reyes N. Molecular identification and antimicrobial susceptibility of Staphylococcus aureus nasal isolates from medical students in Cartagena, Colombia. Braz J Infect Dis. 2012;16(4):329-34.

27. Caceres M. Frequency of nasal carriers of methicillin-resistant Staphylococcus aureus among health workers in Nicaraguan hospitals. Rev Panam Salud Publica. 2011;30(6):610-4.

28. Shittu AO, Okon K, Adesida S, Oyedara O, Witte W, Strommenger B, Layer F, Nubel U. Antibiotic resistance and molecular epidemiology of Staphylococcus aureus in Nigeria. BMC Microbiol. 2011;11:92.

29. Garcia C, Deplano A, Denis O, Leon M, Siu H, Chincha O, Samalvides F, Jacobs J. Spread of community-associated methicillin-resistant Staphylococcus aureus to Peru. J Infect. 2011;63(6):482-3.

30. Bartoloni A, Pallecchi L, Fernandez C, Mantella A, Riccobono E, Magnelli D, Mannini D, Strohmeyer M, Bartalesi F, Segundo H, et al. Low prevalence of methicillin-resistant Staphylococcus aureus nasal carriage in urban and rural community settings in Bolivia and Peru. Int J Infect Dis. 2013;17(5):e339-42.

31. Vieira MA, Minamisava R, Pessoa-Junior V, Lamaro-Cardoso J, Ternes YM, Andre MC, Sgambatti S, Kipnis A, Andrade AL. Methicillin-resistant Staphylococcus aureus nasal carriage in neonates and children attending a pediatric outpatient clinics in Brazil. Braz J Infect Dis. 2014;18(1):42-7.

\section{Submit your next manuscript to BioMed Central and we will help you at every step:}

- We accept pre-submission inquiries

- Our selector tool helps you to find the most relevant journal

- We provide round the clock customer support

- Convenient online submission

- Thorough peer review

- Inclusion in PubMed and all major indexing services

- Maximum visibility for your research

Submit your manuscript at www.biomedcentral.com/submit 